\title{
The concept of coding in learning-memory theory*
}

\author{
ARTHUR W. MELTON \\ University of Michigan, Ann Arbor, Michigan 48104
}

\begin{abstract}
The concept of coding, which refers to what is stored in memory during learning, is defended as an important and necessary conceptual advance in learning-memory theory during the last decade. It is maintained that the concept covers a wide variety of functionally different coding operations, with many specifics of its operation still to be experimentally determined, and that attempts to restrict its meaning to arbitrary transformational coding, as suggested by Restle, should be rejected. The paper comments on the empirical contributions to coding theory by Johnson, Wickens, Martin, and Postman and Burns in the symposium for which it served a discussant function.
\end{abstract}

However underdeveloped the concept of coding and a coding theory of human learning and memory may be at this time, coding is too firmly rooted in the theory, hypotheses, and experimental manipulations of contemporary analyses of human learning and memory to be waved aside, as Restle (1973) appears to want to do. The coding concept is one of the important causes, if not the most important cause, of the extraordinary advance in knowledge and theory of human memory in the last 10 years, and its introduction and development is the most important product of research in these 10 years. The papers by Johnson $(1970,1972)$, Martin (1973), Wickens (1973), and Postman and Burns (1973) highlight some of the most significant ideas and issues that stem from the coding concept: Johnson applies it to the understanding of serial response integration as a variable in cue-response learning; Martin makes the variability in coding of nominal cue events the basis for a radical reformulation of an interference theory of forgetting; Wickens provides one empirical base for the conception of the code for a single, unitary event, such as a word, as a multicomponent or multifeature event, as formally modeled by Bower (1967) and Norman and Rumelhart (1970); and Postman and Burns have provided dramatic evidence of the differential functional characteristics of imaginal and verbal codings of word pairs in massed acquisition and long-delayed cued recall. But, however important these examples may be, they are but samples of the way in which the concept of coding has altered traditional conceptions of event and associative learning and memory, others being the analysis of very short-term, or "primary," memory (e.g., Craik, 1971), the interrelations of short- and long-term memory (e.g., Baddeley \& Patterson, 1971), the contextual determinants of recognition memory (e.g., Tulving \& Thompson, 1971), and the mechanism of the effectiveness of repetitions in learning (e.g., Madigan, 1969; Melton, 1970), to name a few. Many other applications and discussions of the coding concept may

*This paper is a revision, with some elaboration, of what was said as a "discussant" at the symposium. Such elaboration was not feasible at the symposium owing to time constraints. be found in recent books on memory edited by Tulving and Donaldson (1972) and Melton and Martin (1972).

Before commenting in more detail on the symposium papers mentioned above, Restle's less than enthusiastic comments on the coding concept require a rejoinder, during the course of which the meaning of coding in learning-memory theory and investigation may become less controversial. To a considerable extent my rejoinder is bound to be a semantic exercise-perhaps Restle intended this outcome-since the coding concept has been introduced into learning-memory theory in order to take into account the now obvious interaction of the cognitive structure and processes of the learner with input information in producing what is stored in the memory trace, engram, or "code" for the event. Restle is quite willing to accept perceptual responses, including perception of relations and rules and the generation of "hypotheses," as cognitive structure interactions with input events and must accept persistence of these subjective events in memory; therefore, he accepts the basic idea embodied in the concept of coding as I and others are using it.

However, Restle chooses to put some meanings into the concept of coding that $I$, and I suspect many others, find quite foreign to our intent. He identifies a code and coding with a system or systems of arbitrary, artificial, and fixed transformations of input information in the flow of information from perception to long-term memory, as though admittedly arbitrary mnemonic systems ("one is a bun, two is a shoe," etc.) and what are properly called "substitution codes" or "ciphers" (Liberman, Mattingly, \& Turvey, 1973, p. 331) are prototypes of what the coding concept is about, rather than sometimes bizarre and idiosyncratic instances encompassed by the concept. The same theme is developed in his contrast of "blind" memorizing and "true" learning, the former somehow equated with coding, and in the implication throughout his paper that codes are "bad," while whatever Ss are doing in his learning theory is "good."

It would be unwise to allow this misconception of the coding concept to go unchallenged and uncorrected, else one of the major conceptual advances in the scientific 
analysis of human learning and memory would be degraded, if not lost. Until about 10 years ago, this field of effort had a very limited set of conceptual tools (forward, backward, remote, contextual, and mediate associations) and these were employed in describing the relations of nominal stimulus and response events. Lawrence (1962) and Underwood (1963) introduced the concept of the stimulus as coded and the distinction between the nominal stimulus and the functional stimulus (the stimulus as coded). They made clear the uncertainty relation between the nominal and functional stimuli, which became generalized by Martin (1968) in his concept of stimulus encoding variability. Response learning, which Underwood and Schulz (1960) had differentiated from associative learning, was soon recognized to partake of coding in the form of "chunking," following Miller (1956) and following subsequent evidence for serial, categorical, and subjectively generated higher order units in short-term memory and free recall experiments. Meanwhile, a wide variety of studies of short-term and long-term memory were providing evidence that the nature of coding responses and, therefore, the nature of what was stored in memory, varied as a function of modality of presentation (and the spatial or temporal organizations natural to these modalities), the availability of cross-modality (e.g., verbal representation of visual events, spatial imaginal representations of auditory verbal events) or interclass transformations (e.g., natural language elaborative coding of meaningless trigrams such as XFZ, sentential coding of arbitrary "unrelated" words), the applicability of rule or relational representations, and the time allowed for these transformations to occur.

With this background, it is simply not possible at this point in time to make contact with the vast knowledge we have about what is stored in memory and how this affects short-term or long-term retrieval, or the effects of further repetitions, without having concepts to describe what is stored in memory as differentiated from what was presented for storage in memory. But the coding concept is metatheoretical and implies no constraints on what can be accepted as a coding response to a stimulus (or cue) and response term in associative learning. It can even accommodate a situation in which there is maximum isomorphism between the nominal and functional (coded) events, as might be the case when the infant learns to say "dada" to a certain class of compound visual patterns involving a mustache. It is certainly not a concept restricted to "good" codes or "bad" codes, to "true" learning or to raw unmediated association through contiguity, nor to one theory of the ontogenesis of feature development ("extraction" of information in the stimulus) or another (elaborative or "enrichment" of associative coding).

Coding is the core concept of what might well be termed a new dynamic structuralism of mental events in which the information processing activities of the learner define the structure of stored traces and these in turn define what is retrievable and what is retrieved, but again with no constrainis based on awareness of either the coding process or its product, the code. The components of the code may be automatic, presumably based on built-in organismic properties or on highly overlearned specific habits and structures or information processing skills, or optional, as in rehearsal and recoding operations and the generation and testing of "hypotheses" tailored to the requirements of specific tasks. The latter are, I suspect, what Restle thinks of as "true" learning. However, the coding concept has been formulated to aid the description and understanding of what human organisms do when an experience has a demonstrable effect on later performance that can be related to that experience, even such "stupid" things as remembering telephone numbers over short or long periods of time, remembering where the car was parked, learning the meaning of new acronyms, and learning the arbitrary names our language has assigned to common objects, none of which have any inherent structure to be extracted. In fact, one of the prime contributions of the coding concept to contemporary research and theory is that it can and does serve as a common focus for those of us, like myself and Underwood (1969), who come out of traditional associationistic metatheory, and like Asch (1969), who represents the antiassociationistic Gestalt metatheory, as well as to those (Atkinson \& Wickens, 1971; Estes, 1969) concerned with the role of motivation and reinforcement in human learning. This accommodation to a single conception of what the problem is should not be denigrated by arbitrary constraints on what a code may be.

One can, of course, maintain that the coding concept is so general that it means nothing, and even I become somewhat concerned with the abandon with which investigators and theorists invent "tags" for any feature or attribute of an experience that can be shown to support discriminative responding in a retention test. But even here a component of the code or memory trace is being specified, and coding theory must encompass such components and eventually understand them. Similarly, "codes" will be used by many as mere synonyms for memory traces, with no specificity whatsoever, but as knowledge and alternative theoretical models of coding processes develop, it is to be expected that allowable inferences about the functional and structural characteristics of codes and components of codes will become precise and the ways in which codes of nominally different events become associated in higher order codes, especially as a function of their compositional structures, will become specifiable. Much has already been accomplished in such a program (e.g., Melton \& Martin, 1972), and several of the critical ideas 
and issues are represented in this symposium, to which I will now turn.

Johnson's paper summarizes his recent (Johnson, 1970,1972 ) analyses of serial event memory in terms of an E-induced or S-imposed hierarchy of aggregative units he calls "codes." Although he has shown that his measures and theory have applicability to veridical memory for sentences, much of the research is concerned with the serial organization of random letter strings of Length 3 to Length 9, i.e., the kinds of strings commonly employed in memory span studies. However, his work is better described as analysis of the processes involved in the response-learning component of paired-associate learning, using an ingenious paired-associate paradigm in which the number of pairs to be learned is small (two to four), the cue terms (single digits) minimize stimulus, and the multiple trials required for learning allow observation of the growth and stabilization of serial response organization. Previous work on serial response learning in paired-associate learning (e.g., Underwood \& Schulz, 1960; McGuire, 1961) had been restricted to very short strings (one, two, or three elements) and the effects of meaningfulness of the sequences, as variously defined. Johnson's work, therefore, attacks more directly the issue of learning of serial events under conditions of concurrent interference from other serial events.

The hypothesis that such learning involves the development of subjective units (codes) for groups of elements within the string is well supported by the use of transition error probabilities (TEPs). These TEPs are low within codes and high between codes, and it is demonstrable that interference operates primarily between codes, rather than between elements within codes, although a number of problems of interpretation remain. In my judgment, this is an important contribution to coding theory because: (a) it attacks the relatively neglected problem of serial response learning, provides data with which any theory of such learning must come to terms, and provides a well formed theory based on the coding concept with which other recently developed theories (Bower \& Winzenz, 1969; Estes, 1972; Restle \& Brown, 1970) may be compared; (b) it provides a distinctively different method, which has continuity with the traditional paired-associate method, and a universally useful measure (TEPs) for observing subjective organization in serial learning under conditions ranging from arbitrary grouping of random input information to the extraction of embedded relations among input events.

The principal concern of Wickens's (1973) paper is with the notion that the coding response to individual words is a compound event having components that code physical properties of the input event and other components that code denotative and connotative meanings of the word. If one accepts the inference that release from proactive interference indexes a shift in the coding response at the time of storage, his data argue for a multicomponent conception of the codes for input events, such as words, that have deep embedding in semantic memory. Clearly, semantic components of the code are dominant over direct representational components ("physical"), although modality of input may provide a dominant discriminative feature under some conditions. It should, of course, be remembered that his short-term memory tests after $20 \mathrm{sec}$ represent memory at or near asymptote in such experiments and reflect residual coding in long-term memory, rather than the coding or component dominance that might be present in very short-term or "primary" memory (Waugh $\&$ Norman, 1965). Other research methods are necessary for detection of such transient code components or their relative dominance (e.g., Shulman, 1970). Nevertheless, given such boundary conditions, it seems to me very important that he has been able to provide evidence for the hypothesis that code components operate independently and additively to determine release from proactive interference. Although other investigators of memory may question the complexity of the code inferred by Wickens (Underwood, 1972), may question whether the PI buildup and release are acquisition effects, rather than retrieval effects based on differential coding at acquisition (Underwood, 1972), or may question, as do Postman and Burns (1973), whether the discriminative cue for release from PI need reflect a shift in coding at the time of storage, there can be no doubt that Wickens has provided a substantial body of data on the composition of coding responses to words and that this is a critical theoretical issue in coding theory.

Although it seems to me that there is sufficient evidence, other than that provided by the PI release experiment, to support the assumption that the coding response to a word (or triad of words) has multiple components, it is of critical importance to determine the validity of Wickens's inference and of the alternative inferences that have been proposed. I have heard about, and no doubt all of us will soon see, experiments that attempt to test one or more of the alternative interpretations of PI development and release. For a phenomenon as robust as PI buildup and release in the Brown-Peterson short-term memory paradigm and as potentially important for the development of coding theory, it would seem that psychologists might at least this once devote the concentration of effort and ingenuity necessary to achieve an agreed upon conclusion regarding its interpretation.

Martin's (1973) paper also focuses on a central issue in coding theory; namely, the concept of coding variability, whereby the same nominal stimulus event may elicit different coding responses on different occasions. Although there may be an "intrinsic" encoding variability that is an increasing function of 
time between two occasions of the nominal stimulus, however that time may be filled with activity, it seems probable that encoding variability of unitary events, such as words. is principally determined by the information processing context (usually other words) in which the nominal word occurs. Persuasive evidence for such contextual effects have been obtained in studies of recognition memory (e.g., Light \& Carter-Sobell, 1970; Tulving \& Thompson, 1971). Since this is so, it is but a short step to the notion that the nominal response term of a pair in paired-associate learning is the principal context of the nominal stimulus term (paired-associate methodology makes it so) and influences the stimulus coding both selectively and elaboratively. With this essentially straightforward development of coding theory, Martin is able to accommodate data on interference in forgetting that seem troublesome to other contemporary versions of interference theory. 1 find this a stimulating way of thinking about interference effects in learning and forgetting and a way that could not be had until the question of what is stored is faced in coding terms.

This is not to say, however, that all the data and theory related to unlearning, recovery, and differentiation are out the window. Rather, it seems to me that his theory says that the locus-or at least one locus-of interference in learning and in remembering is in the coding of the cue or stimulus term. Whether all the phenomena and data on interference in learning and remembering will fall in line with Martin's theory remains to be seen, but I suspect not. There is, and has been, an unstated assumption in the efforts to develop an interference theory of forgetting, which is that one or a very limited set of mechanisms will account for all production of forgetting through interference, be it reproductive inhibition (competition), specific associative unlearning plus competition, response set suppression, differentiation, cue-response codes, or whatever. It seems to me that we should consider the possibility that nature is not that simple or that, if it is that simple, then we will need to achieve an extraordinarily complex, comprehensive, and quantitative theory based on one of these simple ideas in order to reveal the simplicity of nature.

Although the Postman and Burns (1973) paper presents some interesting cautionary remarks about coding in general, I choose to focus on their neat demonstration that an effective form of associative coding (imagery) for the short intertrial retention intervals involved in massed multitrial learning may be ineffective, and perhaps less effective than another form of associative coding (verbal), for long-term retrieval. While one experiment does not a principle make, their point is well taken that earlier experiments failed to equate degrees of original learning and, thus, confound degree of original learning and measures of long-term retention. This design error may be even more egregious when the various kinds of pairs are mixed within a single list, and Ss may perform selective rehearsal both during original learning and between the learning and delayed retention, as in the experiments by Butter and Palermo (1970) and Yuille (1971). The Postman and Burns study is of particular importance for further research on coding processes because it must be expected that different components of the coding response will have different rates of loss of accessibility over time or intervening events. Up to this time, this question has drawn substantial attention only with respect to acoustic and semantic components (Baddeley \& Patterson, 1971). It is time that coding components and structures be examined for their effects on truly long-term retrieval, and it is to be hoped that the measurement and design problems involved in comparing rates of forgetting when rates of learning are different (Underwood, 1964) will not be ignored.

Although impressed by the Postman and Burns findings, I am somewhat puzzled by certain aspects of them and will want to see other data before accepting the notion of greater persistence of verbal encodings as compared to imaginal encodings. They find concrete stimulus words no better than abstract stimulus words for long-term response recall when responses are abstract words. Recognition memory for concrete words is better than that for abstract words (Gorman, 1961), and Martin (1967) and others have shown that stimulus recognition is a necessary condition for response recall. Why did not those effects operate in the Postman and Burns study? There are perhaps many reasons, among them, of course, the question whether recognition memory is, in fact, different for concrete and abstract words after long retention intervals when degrees of original learning have been equated. Or it may be, as Postman and Burns suggest, that the explanation of long-term cued recall of specific words must be found in the way in which response terms influence stimulus coding during learning, as Martin (1972, 1973) hypothesizes, or in the differential specificity of decoding from imaginal and verbal codes following their retrieval. It is to be hoped that these findings and speculations will be a motivating challenge for the ingenious use of recognition, recall, and joint recognition-recall measures in further research. However that may be, the important point at this time is that the experiments and theory must be aimed at determining what is stored in memory and how what is stored determines responses at the time of attempted retrieval under different conditions of cuing.

There is as yet no comprehensive statement of coding theory that attempts to describe the structural and functional properties of encoding events and processes. Even so, the concept of an encoding process as descriptive of what an observer or learner does in 
reacting to and storing in memory an event, pair of events, or sequence of events, and the concept of a code as descriptive of what has been stored may well represent a genuine Kuhnian "paradigm shift" in the scientific analysis of human learning and memory. There will certainly be some, if not many, who consider this statement false, if not foolish. Only time and the ingenuity of those who have adopted the general tenets of coding theory as their theoretical and experimental guidelines will tell. Whatever may be the final outcome, I am confident that we will have gained substantial new knowledge about learning and memory as a consequence of the coding concept, knowledge and understanding that we would not have gained otherwise.

\section{REFERENCES}

Asch, S. E. A reformulation of the problem of associations. American Psychologist, 1969, 24, 92-102.

Atkinson, R. C., \& Wickens, T. D. Human memory and the concept of reinforcement. In R. Glaser (Ed.), The nature of reinforcement. New York: Academic Press, 1971. Pp. 66-120.

Baddeley, A. D., \& Patterson. K. Relation between long-term and short-term memory. British Medical Bulletin, 1971, 27, 237-242.

Bower, G. A multicomponent theory of the memory trace. In $\mathrm{K}$. W. Spence and J. T. Spence (Eds.), The psychology of learning and motivation. Vol. 1. New York: Academic Press, 1967.

Bower, G., \& Winzenz, D. Group structure, coding, and memory for digit series. Journal of Experimental Psychology Monograph, 1969, 80(May, Part 2), 1-17.

Butter, M. J., \& Palermo, D. S. Effects of imagery on paired-associate recall as a function of retention interval, list length, and trials. Journal of Verbal Learning \& Verbal Behavior, 1970, 9, 716-719.

Craik, F. I. M. Primary memory. British Medical Bulletin, 1971, $27,232-236$

Estes, W. K. Reinforcement in human learning. In J. T. Tapp (Ed.), Reinforcement and behavior. New York: Academic Press, 1969. Pp. 63-95.

Estes, W. K. The associative basis for coding and organization in memory. In A. W. Melton and E. Martin (Eds.), Coding processes in human memory. Washington, D.C: Winston \& Sons, 1972. Pp. 161-190.

Gorman, A. M. Recognition memory for nouns as a function of abstractness and frequency. Journal of Experimental Psychology, 1961, 61, 23-29.

Johnson, N. F. The role of chunking and organization in the process of recall. In G. H. Bower (Ed.), The psychology of learning and motivation. Vol. 4. New York: Academic Press, 1970. Pp. 172-247.

Johnson, N. F. Organization and the concept of a memory code. In A. W. Melton and E. Martin (Eds), Coding processes in human memory. Washington, D.C: Winston \& Sons, 1972. Pp. 125-159.

Lawrence, D. H. The nature of a stimulus: Some relationships between learning and perception. In $S$. Koch (Ed.), Psychology: A study of a science. Vol. 5. New York: McGraw-Hill, 1963. Pp. 179-212.

Liberman, A. M., Mattingly, I. G., \& Turvey, M. T. Language codes and memory codes. In A. W. Melton and E. Martin (Eds.), Coding processes in human memory. Washington, D.C: Winston \& Sons, 1972. Pp. 307-334.

Light, L. L., \& Carter-Sobell, L. Effects of changed semantic context on recognition memory. Journal of Verbal Learning \& Verbal Behavior, 1970, 9, 1-11.
Madigan, S. W. Intraserial repetition and coding processes in free recall. Journal of Verbal Learning \& Verbal Behavior, 1969, 8, 828-835

Martin, E. Relation between stimulus recognition and paired-associate learning. Journal of Experimental Psychology, $1967,74,500-505$

Martin, E. Stimulus meaningfulness and paired-associate transfer: An encoding variability hypothesis. Psychological Review, $1968,75,421-441$.

Martin, E. Stimulus encoding in learning and transfer. In A. W. Melton and E. Martin (Eds.), Coding processes in human memory. Washington, D.C: Winston \& Sons, 1972. Pp. 69-84.

Martin, E. Memory codes and negative transfer. Memory \& Cognition, 1973, 1, 495-498.

McGuire, W. J. A multiprocess model for paired-associate learning. Journal of Experimental Psychology, 1961, 62, 335-347.

Melton, A. W. The situation with respect to the spacing of repetitions and memory. Journal of Verbal Learning \& Verbal Behavior, 1970, 9, 596-600.

Melton, A. W., \& Martin, E. (Eds.), Coding processes in human memory. Washington, D.C: Winston \& Sons, 1972.

Miller, G. A. The magical number seven plus or minus two: Some limits on our capacity for processing information. Psychological Review, 1956, 63, 81-97.

Norman, D. A., \& Rumelhart, D. E. A system for perception and memory. In D. A. Norman (Ed.), Models of human memory. New York: Academic Press, 1970. Pp. 21-66.

Postman, L., \& Burns, S. Experimental analysis of coding processes. Memory \& Cognition, 1973, 1, 503-507.

Restle, F. Coding and the detection of patterns. Memory \& Cognition, 1973, 1, 499-502.

Restle, F., \& Brown, E. Organization of serial pattern learning. In G. H. Bower (Ed.), The psychology of learning and motivation. Vol. 4. New York: Academic Press, 1970. Pp. 249-331.

Shuiman, H. G. Encoding and retention of semantic and phonemic information in short-term memory. Journal of Verbal Learning \& Verbal Behavior, 1970, 9, 449-508.

Tulving, E., \& Donaldson, W. Organization of memory. New York: A cademic Press, 1972.

Tulving, E., \& Thompson, D. M. Retrieval processes in recognition memory: Effects of associative context. Journal of Experimental Psychology, 1971, 87, 116-124.

Underwood, B. J. Stimulus selection in verbal learning. In C. N. Cofer and B.S. Musgrave (Eds.), Verbal behavior and learning: Problems and processes. New York: McGraw-Hill, 1963. Pp. 33-48.

Underwood, B. J. Degree of learning and the measurement of forgetting. Journal of Verbal Learning \& Verbal Behavior, $1964,3,112-129$.

Underwood, B. J. Attributes of memory. Psychological Review, 1969, 76, 559-573.

Underwood, B. J. Are we overloading memory? In A. W. Melton and E. Martin (Eds.), Coding processes in human memory. Washington, D.C: Winston \& Sons, 1972. Pp. 1-23.

Underwood, B. J., \& Schulz, R. W. Meaningfulness and verbal learning. Chicago: Lippincott, 1960.

Waugh, N. C., \& Norman, D. A. Primary memory. Psychological Review, 1965, 72, 89-104.

Wickens, D. D. Some characteristics of word encoding. Memory \& Cognition, 1973, 1, 485-490.

Yuille, J. C. Does the concreteness effect reverse with delay? Journal of Experimental Psychology, 1971, 88, 147-148.

(Received for publication August 24, 1973.) 